\title{
Harvesting Period and Yield of Pleurotus sajor-caju on Different Agro-Substrate
}

\author{
Kamlesh K. Gautam* and Daya Ram
}

Department of Botany, Udai Pratap (Autonomous) College, Varanasi-221006 (UP) India

College of Agriculture, Central Agricultural University, Imphal, Manipur-795004 (India)

*Corresponding author

\section{A B S T R A C T}

\section{Keywords}

Pleurotus sajorcaju, Cultivation, Harvesting period and Substrate

\section{Article Info}

Accepted: 04 August 2019 Available Online: 10 September 2019
Pleurotus sajor-caju, a nutrient rich mushroom was cultivated on four different substrates, viz. Wheat straw, Paddy straw Maize stalk and Typha Leaves substrates. It was observed Wheat straw followed by paddy straw Wheat straw, Maize stalk and Typha Leaves. The third harvesting was complete in 42 days in case of wheat straw, which was statistically more compared to paddy straw and maize stalk. The effect of various substrates on the yield of fresh mushroom the result indicated that higher yield of $475.00 \mathrm{~g} 1 / 2 \mathrm{~kg}$ was obtained on wheat straw followed by paddy straw and maize stalk, the minimum yield of basidiocarp of $285 \mathrm{~g} 1 / 2 \mathrm{~kg}$ was recorded in Typha Leaves.

\section{Introduction}

Food production in large quantity is a challenge but safe disposal of crop residues is a great problem. Edible fungi are natural recycler which converts lignocelluloses wastes into protein rich health food. Malnutrition is a problem in developing third world countries. The Food and Agriculture Organization have recognized mushrooms as food contributing protein nutrition to the countries depending largely on cereals.

Pleurotus species is simply a micro fungus. Cultivation in rural area helps to solve the problem of agro-waste management in a profitable way by producing a highly nutritious food item the mushrooms along with upliftment of those area. $P$. sajor-caju the most common oyster mushroom species, on dry weight basis contains protein $47.93 \%$, reducing sugar $0.28 \%$ ascorbic Acid $0.06 \%$, ash $8.25 \%$ non reducing sugar lacking starch 9.12\% and fat 2.26\% Bahl, (1994) and Dhoke (2001). High Potassium to sodium ratio contain in pleurotus species helps to cure patients suffering from hypertension and heart diseases, Mushroom as an excellent Food source to alleviate Malnutrition in developing countries due to their Flavor, Texture nutritional value and high productivity per unit area. Pleuroturs sajor-caju prefers different 
agro wastes for its cultivations. The present investigation was planned with the objective to study the effect of different agro-wastes on harvesting and yield of basidiocarp of $P$. sajor-caju. In view of above facts and notions, the present study was carried out with the specific objective viz to measure of harvesting Period and Yield of Pleurotus Sajor-Caju on Different Agro-Substrate.

\section{Materials and Methods}

Experiment was conducted during 2011-12 in plant pathology and Eco-pathology Lab, Department of Botany, U.P. College Varanasi. The pure culture of Pleurotus Sajor-caju was maintained in MEA slants used for preparation of master and mushroom seed OR spawn used in present study.

\section{Preparation of spawn}

The success of mushroom production depends on selecting the ideal seed material (Spawn). The mycelium of mushroom fungus is multiplied on a grain bask for the purpose of mushroom production and is called spawn. The spawn of Pleurotus sajor-caju was prepared on wheat grains by grains by technique already described by lamke (1972) and slightly modified by Awasthi and Singh (1993). Wheat grains were washed in tap water and boiled. The excess water was drained off and wheat grains were spread over blotting paper sheet for soaking of excess water calcium carbonate and calcium sulphate (Gypsum) were mixed at the rate of 0.5 and $2.0 \%$ respectively and dry weight basis with boiled grains of wheat. Thereafter, 300 gram grains per bottle were filled in empty glass bottles (500 ml Capacity) and plugged with cotton. The plugs were wrapped with aluminum foil and stream sterilized for $2 \mathrm{hrs}$ at $15 \mathrm{lb}$ pressure in an autoclave. The sterilized and cooled bottles were inoculated under aseptic condition, with cultures of
Pleurotus sajor-caju. The bottles got nearly half filled in 10 days and full in 18-21 days with white mycelia growth and were used for production of $P$. sajor-caju.

\section{Cultivation}

Various plant materials viz, wheat, Paddy, Fenugreek, Maize and Typha Leaves were used to study the harvesting period and yield of basidiocarp $P$. sajor-caju. The standard polythene bag method of cultivation was used. The polythene bags of 70-100 gauges thickness and $35 \times 45 \mathrm{~cm}$. sizes were used, which was sufficient to accommodate 500 gram of dry weight straw, the bag was provided with five vent holes at bottom and 34 at top. The polythene bags were sterilized in $2 \%$ formalin by dipping. The lower corners of the bags were tied with string so that the bed assumed a round shape after filling the straws. The dry weight substrates were chopped to small pieces $(3-5 \mathrm{~cm})$ and socked in cold water for 3-5 hrs. After soaking, the substrate was taken out and the excess of water drained of these substrates were then sterilized in autoclaved at $15 \mathrm{lb}$ P.S.I. for 15-30 min. After autoclaving the substrate was cooled down to filling the polythene bags. The organic mixture @ 1\% i.e.20 gram dal powder per bags.

The growing room used was partially ventilated with diffused light. The relative humidity was maintained above $80 \%$ by sprinkling the walls and floor with water and the temperature was maintained range 22-26 ${ }^{\circ} \mathrm{C}$. Due care was taken for proper air circulation. The procedure of Bahl (1988), Singh et al., (1995), Dhoks et al., (2001) was adopted with certain modifications for cultivation of $P$. sajor-caju. Daily observations were recorded for total harvesting period and yield of basidiocarp of $P$. sajor-caju on different substrates. 


\section{Results and Discussion}

Harvesting period of $P$. sajor-caju on different for $1^{\text {st }} 2^{\text {nd }}$ and $3^{\text {rd }}$ picking presented in Table 1. The Harvesting period of Pleurotus sajor-caju for third picking varied from 42-43 days in various substrates. The day required for first packing indicated, that wheat straw took 22 days to produce first harvesting mushroom, with regard to paddy straw they took 21 days to produce first crop of harvestable mushroom and a minimum of 19 and 20 day required for Typha Leaves for the first picking of mushrooms. For second Harvesting Typha Leaves took maximum were day (32 days) while wheat straw took minimum (29 days). The third harvesting was complete in 42 days in case of wheat straw, which was statistically more compared to paddy straw and maize stalk. The effect of various substrates on the yield of fresh mushroom the result indicated that higher yield of $475.00 \mathrm{~g} 1 / 2 \mathrm{~kg}$ was obtained on wheat straw followed by paddy straw and maize stalk, the minimum yield of basidiocarp of $285 \mathrm{~g} 1 / 2 \mathrm{~kg}$ was recorded in Typha Leaves. The result obtained were in conformity with patil et al., (1989) and Dhoke et al., (2001) Patil and Jadhav (1997) who also reported good growth of Pleurotus spp. on paddy straw and wheat straw.

Table.1 Effect of different substrates on harvesting period (days) and Yield of basidiocarp (g) of Pleurotus sajor-caju

\begin{tabular}{|l|c|c|c|c|c|c|c|}
\hline \multirow{2}{*}{ Substrates } & \multicolumn{7}{|c|}{ Average yield of basidiocarp/500g dry weight of substrate } \\
\hline & \multicolumn{2}{|c|}{$\mathbf{1}^{\text {st }}$ Picking } & \multicolumn{2}{|c|}{$\mathbf{2}^{\text {nd }}$ Picking } & \multicolumn{2}{|c|}{$\mathbf{3}^{\text {rd }}$ Picking } & Total \\
\cline { 2 - 8 } & Day & yield & Day & yield & Day & yield & yield \\
\hline Wheat straw & 22 & 300 & 29 & 120 & 42 & 50 & 470 \\
Paddy straw & 21 & 270 & 30 & 100 & 42 & 40 & 410 \\
Maize stalk & 20 & 200 & 30 & 80 & 42 & 40 & 320 \\
Typha Leaves & 19 & 176 & 32 & 75 & 43 & 35 & 285 \\
\hline
\end{tabular}

It is therefore recommended to grow mushroom $P$. sajor-caju on the substrate of wheat straw, paddy straw, maize stalks and Typha Leaves which are easily available and have a higher yield of basidiocarp of Pleurotus sajor-caju.

\section{Acknowledgement}

The authors acknowledge the contributions of Kamlesh K. Gautam and Daya Ram Department of Botany, Udai Pratap (Autonomous) College Varanasi and College of Agriculture, Central Agricultural
University, Imphal, for their technical support and valuable contributions to the manuscript.

\section{References}

Bahl, N. (1988) Handbook on Mushroom. Oxford and IBN Publ. New Delhi, pp: 1-8.

Bahl, N. (1994) Handbook on Mushroom. $2^{\text {nd }}$ edn. Oxford and IBN Publ. Pvt. Ltd. New Delhi, pp: 97-104.

Chang, S.T. and Miles, P.G. (1993). Edible Mushrooms and their cultivation, CBS pbl. New Delhi, pp: 8-40 
Dhoke et al., (2001). Cropping period and yield of oyster mushroom Pleuroturs sajor-caju on different agro-substrate.

Gautam K.K. (2015). Harvesting period and yield of P. Florida on different agrosubstrate 2015, Tatvanveshan. 2, 7982

Patil, B.D., Jadhav, S.W. and Kakade, D.S. (1989). The studies on cultivation of Pleuroturs sajor-caju on different substrate. J. Maharashtra Agri.
University 14; 156-158

Patil, M.B. and Jadhav, V.T. (1997) studies on productivity of oyster mushroom on different agro-wasted under marathawada condition. $J$. Maharashtra Agri. Univ. 24: 162-163

Singh A.K., Awasthi and Rai B. (1965) Utilization of sugarcane trash for production of oyster mushroom. Mus. Res. Dev. 9: 35-38.

\section{How to cite this article:}

Kamlesh K. Gautam and Daya Ram. 2019. Harvesting Period and Yield of Pleurotus sajorcaju on Different Agro-Substrate. Int.J.Curr.Microbiol.App.Sci. 8(09): 394-397.

doi: https://doi.org/10.20546/ijcmas.2019.809.048 